\title{
2006-2061: MUSIC IN MATLAB: PROGRAMMING CHALLENGES FOR AN INTRODUCTORY COURSE
}

\section{S. Scott Moor, Indiana University Purdue University-Fort Wayne (ET)}

Scott Moor is an Assistant Professor of Engineering and Coordinator of First-Year Engineering at Indiana University Purdue University - Fort Wayne. He received a B.S. and M.S. in Chemical Engineering from M.I.T. After over a decade in industry he returned to academia at the University of California at Berkeley where he received a Ph.D. in Chemical Engineering and an M.A. in Statistics. He is a registered Professional Chemical Engineer in California. He is active in the development of spaces and activities that encourage "serious play" and cooperative learning. 


\title{
Music in MATLAB: \\ A series of programming challenges for an introductory course.
}

\begin{abstract}
Students often find their first course that includes programming a difficult new world. First-year students may not be inspired by programs that input numbers, perform a calculation and then output a number. To help motivate students there are many examples of courses using robotics or graphics projects and problems to provide a more concrete result for programming exercises. MATLAB's ability to output a time series to the sound card of a PC provides an opportunity for problems that create sounds and music instead of numbers. This approach requires little or no equipment to implement.
\end{abstract}

Over the past year and a half, we have developed problems and small projects for an introductory computer tools course where MATLAB is taught. Music and sound form the basis of challenges with a range of topics and difficulties. Problems have been developed that illustrate almost all aspects of the course from a script that plays a very simple tune to a general song player that reads a data file containing the note names, durations and amplitudes. This player illustrates the use of loops, conditionals and several sub-functions.

Other project problems include functions to distort a .wav file illustrating file handling, a stereo player illustrating arrays, graphing a wave file illustrating graphing issues, adding harmony to illustrate array calculations, converting note names to frequencies illustrating the use of a switch structure or a complex calculation. More advanced projects can include adding attack and decay to notes, random generation of notes, developing a wind chime simulator and analysis of sound waves using a preprogrammed FFT function. Problems build over the course of the semester as students develop their ability with the software.

In addition to developing students understanding of computer manipulations they are introduced to a range of important engineering topics including: waves, wave shape, sampling, digital representation of analogue phenomenon, sound, signal processing, analogue/digital conversion and bit resolution.

These projects have added an interesting variation into the course. The students have found these projects challenging, and it has been important to develop aids to help them understand working with sound. Particularly important is providing materials to help students who have little or no musical training. This paper includes a discussion of the various problems and projects used and the lessons learned in implementing them.

\section{Introduction}

In a recent assessment of their first-year engineering program, Notre Dame found that their greatest student attrition coincided with a first semester programming module. ${ }^{1}$ This result is not unusual. First-year students often find programming a challenging topic. ${ }^{2}$ In addition to 
having difficulty with the precise structure of programming, students often lack the ability to appreciate the importance of the applications that are used.

Using MATLAB's ability to send a time series to the sound card offers a simple response to these issues and has several advantages in an introduction to computer tools and programming class. Sound projects allow students to develop programs that effect the world around them. They are able to work on something that there non-technical friends and family can appreciate. Sound projects also introduce a range of important engineering topics that first-year students may not have realized exist. This range includes signal processing, acoustics, and analogue to digital conversion among others.

There are many examples of music projects and experiments being used in a range of courses. Projects for introductory physics classes have been discussed in the literature. ${ }^{3,4}$ An excellent paper on the mathematics of music utilizing MATLAB is available. ${ }^{5}$ In addition, I have used MATLAB to test chime notes in the construction of wind chimes for a project in an introductory engineering design class. ${ }^{6}$ Simple music has been used as an example in an introductory circuits class at Rowan University. ${ }^{7}$ A sound filter project using MATLAB has been used in a Digital Signal Processing class. ${ }^{8}$

In this paper we examine the use of music in teaching engineering programming in MATLAB. In this approach a series of eight challenge problems are given throughout the semester to illustrate a range of topics and to build toward a final overall music player. This building is designed to help students complete increasingly challenging problems as the term moves on, rather than face a giant project at the end.

\section{Context}

These projects were implemented in an introductory two-credit-hour computer tools class that is part of Indiana University Purdue University - Fort Wayne's (IPFW) first-year engineering program. IPFW's Department of Engineering is a branch campus of Purdue University. We have a relatively open admissions process; so students in the computer tools class come from a very wide range of backgrounds. Approximately $40 \%$ are non-traditional students, and many are working. Their starting mathematics level can vary; however, it is a prerequisite of the course that students be ready to take calculus (i.e., they have completed our pre-calculus class or have tested directly into Calculus I). Approximately 80 students complete this course each year. The class is taught with multiple sections in a computer laboratory with 24 student computers and an instructor's computer. The room is arranged in a workshop style where the rows are perpendicular to the front of the classroom allowing easy interaction between students and instructor. ${ }^{9}$ The class meets twice a week for 75 minutes to allow time for both the instructor to present content, and the students to complete significant computer exercises and tutorials.

\section{Key MATLAB Commands}

Several commands are available in MATLAB for working with sound. Three commands are available to play simple time series in MATLAB: sound, soundsc, and wavplay. All three have 
two key inputs: a time series and a sampling frequency. The input time series may be a single monorail time series or can be an $\mathrm{n} \times 2$ array which will play in stereo.

The sound command is set up to take values between 1 and -1 . Values beyond this range are clipped. Sound is a non-blocking call, and if a second sound command is initiated, it will not wait for the first sound to be complete before the second starts playing

The wavplay command is available only on 32-bit windows computers. When sent a doubleprecision time series it behaves much like sound except by default it is a blocking call.

Therefore a second call to wavplay will wait for the first to be completed. There is an option for making wavplay a non-blocking call. It can also handle input of a range of data types.

The soundsc command is also similar to the sound command except it automatically scales any series to the 1 to -1 amplitude range without clipping.

The commands wavwrite and wavread allow creating and reading of Microsoft wave sound (.wav) files. The beep command creates an immediate beep over the computer speaker and is handy for testing that the system is working. The usual MATLAB installation also includes a data file with a section of Handel's Messiah. This can be played by typing:

$$
\begin{aligned}
& >>\text { load handel } \\
& >>\operatorname{sound}(\mathrm{y}, \mathrm{Fs})
\end{aligned}
$$

\section{Resources}

Several resources are available on the web to help with using music in MATLAB. A Music in MATLAB site was developed from the course materials. ${ }^{10}$ This site includes the detailed assignments and resources handed out to students, the grading rubric used, example song text files and .wav files, a link to a table of frequencies for notes in an equal-tempered scale and links to other resources.

Mark Peterson's website also contains many helpful resources. ${ }^{11}$ His site includes information on the mathematics of music, several example .wav files, graphs of the notes represented by the .wav files and some helpful MATLAB functions including one to plot the power spectrum of a .wav file. Additional projects suggested by Peterson include: preparing the time series to make the sound of various vowels, comparing waves of different frequencies to show the beat frequencies and seeing how a note can be heard from the harmonics even when the note itself is missing. Another interesting resource, is a MATLAB tool box for working with MIDI files. ${ }^{12}$

\section{Music Challenge Problems}

Music challenge problems have been used in a majority of the sections of this class for the past four semesters. These problems were given out with regular weekly problem sets and were due the following week. Most of the problems built to the final two challenge problems. The eight challenge problems given in Fall 2005 and planned for Spring 2006 are briefly reviewed below. 1. Song Script: The first problem was to rewrite a simple MATLAB script. Students were provided with the code for a MATLAB script that would play a simple song. This script is 
shown in Appendix A and was based on suggestions by Dr. Shreekanth Mandayam at Rowan University. ${ }^{7}$ The code in appendix A includes annotations that are provided to the students. Students were then asked to rewrite this script so it played a different tune. It must include at least two notes from the scale that were not used in the example script. This problem is used as both an introduction to the music challenges and as an introduction to writing MATLAB scripts.

2. Using a Sub-function: Students are provided with a function which will generate a pseudosquare wave time series given the frequency, amplitude, duration and sampling frequency. They are expected to modify their previous song script to utilize this function. This exercise gives them experience at calling a subfunction and shows the usefulness of sub-function. A copy of this function is shown in Appendix B. This challenge illustrates both writing a function and utilizing a sub-function.

3. Wav File Distorter: Students create a function which could read in a monorail .wav file, distort it in some way and then play it. Two inputs are expected: the filename and a numerical value to adjust the distortion. This challenge is used when students are learning about reading and writing different types of data files. It also gives them a chance to work with MATLAB's ability to manipulate vectors.

4. Graphing a Musical Note: Students are asked to write a function that will generate the time series for pure sine wave and generate a time series of the same frequency using the makesquare2.m function. The function then creates a plot of both waves so that 3 to 5 cycles were visible. The function is to take inputs of frequency and sampling frequency. Students then use this function to explore the impact of sampling frequency on the waves. This problem is used in conjunction with learning MATLAB's graphing capabilities.

5. Six-note Player: Students create a function that can read in an ASCII file containing the frequency, amplitude and duration of six notes. The function is to create a time series for each of the notes, concatenate them together and then play the resulting six-note "song." This function takes the name of the six-note text file as an argument. This challenge gives students continued practice with writing function, reading data files and manipulating vectors including concatenating the different notes together.

6. Note-to-frequency sub-function: Students develop a function that can convert a note name, such as "A4," to its correct frequency, in this case $440 \mathrm{~Hz}$. This is usually accomplished using a large switch statement but can also be done using an approximate calculation.

7. Song Player: Now students have developed most of the pieces necessary to program a player that can read a file containing the note name, duration and amplitude for any number of notes. This problem requires that they use the subroutine from 6 above along with the psequdosquare wave function (makesquare2.m) they have used before. They also must use a loop to handle the unknown length of the song and determine how to concatenate the note series together. At this stage students are putting together much of what they have learned in the course. They must make intelligent use of sub-functions and of loops to complete this challenge. 
8. Enhanced song player: In the final challenge students enhance their players from 7 in some way. Several suggestions are provided but the problem is left very open-ended. Suggestions provided for the enhanced player include:

1) Experimenting with adding overtones (i.e., harmonics).

2) Make a player able to change the key and tempo of a song. The amount of pitch and tempo change should be adjustable.

3) Develop a player that can play more than one note at a time (that can play chords and harmonies). Either by creating harmonies based on a standard chord or by reading in a second set of notes.

4) Develop a player to play a song in stereo. Again the second channel can be synthesized from the first or it can be read in.

5) Develop a player that automatically plays random notes.

6) In general high notes sound loader than low notes when played at the same amplitude. Develop a scheme for compensating for this effect by decreasing the volume of notes as the pitch increases.

7) Automatically add emphasis on the first and third beat of a measure for a $4 / 4$ tune.

8) Add attack and decay to the notes rather than having them play all at one amplitude.

9) Develop a program that can simulate a wind chime with a given set of notes provided by the user.

\section{Implementation}

The eight challenge problems were spread evenly through out the term as appropriate to the topics that were being covered. Table 1 provides a summary of the eight problems used during the 2005/2006 school year and possible other ways they could be used. This table lists additional information that was provided with the assignments and is available on the web. ${ }^{10} \mathrm{~A}$ standard grading rubric was used for most problems as indicated in Table 1. The standard rubric is shown in Table 2. Figure 1 presents the music distorter assignment as an example of the assignments used. The text for all assignments is also available on the web.

In addition to being used as part of a music theme, most of these problems could be used as an example or as an in class exercise (See the fourth column of Table 1). For two of the assigned problems, an in-class exercise was completed: (1) with the initial script program and (2) with the music distorter.

Music programming was first introduced at the end of the second week of the term, when MATLAB script files were being discussed. In class some basic concepts of creating a tone were explained. Students then created and played a single note at the MATLAB command line by copying a provided example. They were then coached through creating two notes, concatenating them and then playing their two-note "song" at the command line. Finally they were given the chance to enter and try out the example script shown in Appendix A.

When students were learning to read files into MATLAB, they were assigned the music distorter problem. In class we again worked at the command line. This time they created a simple distortion of a music file. Students were shown how to read in a wav-file. They modified the 
sampling frequency and played the time series at the new sampling frequency. This speeding up or slowing down of the song provided a very simple example of distorting a wav-file.

Table 1: Summary of Music and Sound Challenges Used.

\begin{tabular}{llllll} 
Challenge Problem & $\begin{array}{l}\text { Resources } \\
\text { (available on web) }\end{array}$ & $\begin{array}{l}\text { Standard } \\
\text { Rubric Used? }\end{array}$ & $\begin{array}{l}\text { In-class } \\
\text { exercise? }\end{array}$ & $\begin{array}{l}\text { Independent } \\
\text { Problem? }\end{array}$ \\
\hline 1 & Song Script & $\begin{array}{l}\text { Background } \\
\text { example song script } \\
\text { song text files }\end{array}$ & Yes & $\begin{array}{l}\text { Yes, an } \\
\text { example was } \\
\text { used }\end{array}$ & Yes \\
\hline 2 & Using a sub-function & makesquare2.m & Yes & Yes & \\
\hline 3 & wav-file distorter & .wav-files & Yes & $\begin{array}{l}\text { Yes, simple } \\
\text { version used }\end{array}$ & Yes \\
\hline 4 & Graphing a note & & & Yes & Yes \\
\hline 5 & Six-Note Player & & Yes & $\begin{array}{l}\text { Yes, a long } \\
\text { exercise }\end{array}$ & Yes \\
\hline 6 & Note to Frequency & & & & \\
\hline 7 & General Song Player & song text files & Yes & & \\
\hline 8 & Player Enhancement & & & Yes & \\
\hline
\end{tabular}

Table 2: Standard Grading Rubric for most Music Problems

\begin{tabular}{|l|l|}
\hline \multicolumn{2}{|l|}{ Criteria (one point each) - } \\
\hline 1 & Problem clearly laid out: numbered, logical ordering of solution \\
\hline \multicolumn{2}{|l|}{ Separate "User Introduction"/problem setup covering: } \\
\hline 2 & Goal of program presented \\
\hline 3 & Instructions for use of program including filename, inputs and outputs \\
\hline 4 & Steps the program uses are presented \\
\hline Program comments: \\
\hline 5 & Clear introductory comments \\
\hline 6 & Comments listing each variable and units \\
\hline Program logic and performance: \\
\hline 7 & .m file electronic \& print copy included with essentially correct logic \\
\hline 8 & Electronic (soft) copy provided runs \\
\hline 9 & Program (soft copy) produces desired output \\
\hline 10 & Output (soft copy) completely fulfills the goal of the program \\
\hline
\end{tabular}


Music Challenge: wav-file distorter

Create a function that reads in a .wav file and then can manipulate how it sounds, play it and save it as a new .wav file. Several means can be used to manipulate the sound file:

- Our in-class example - changing the sampling frequency: If you double the sampling frequency when you play a time series, you will double its frequency and therefore raise the pitch by one octave (or if you cut it in half you will lower the pitch by one octave). A shift of 5.9\% will shift approximately one half step.

- Adding an Echo Effect: Make two copies of the time series, delay one of them and play them together to create an echo effect. The two time series must be the same length for this to work. You will need to either "trim" (remove parts of the time series) and/or "pad" (add series of zeros to fill out series) to accomplish this. To combine the two series you can either add them together (not concatenate but an element-by-element addition) or play them using the stereo capability of the sound command (see the help for sound). If you add two series together you, should divide all the elements by two in order to preserve the original maximum amplitude. You may want to lower the amplitude of the echoed series.

- or you may propose one of your own.

The user should be able to input the name of a .wav file and some parameters for the distortion. Then the file should play the result. You can use any .wav file you like for testing. You can find several simple .wav files by clicking on the "Web Page of Resources" link on the course web page under "Music in MATLAB".

Figure 1: Example Music Challenge - The .wav-file distorter

\section{Instructor's observations}

Several patterns were observed in student's work and comments. The most energetic classes of the term included the in-class sound and music exercises. Students clearly enjoyed the sound coming out of their machines. In addition top students clearly "got into" the music projects often going well beyond what was required and voicing their enjoyment of the projects.

No musical background was required or expected for any of the problems. However, some students still had a great deal of fear of music. Help and encouragement was necessary for these students to be comfortable with music as part of an engineering course.

The approach of using a series of challenge problems to form an overall project helped students step through the new material. The first time that I used a music/sound theme in this class I did not use challenge 5 - six-note player, or challenge 6 - note to frequency subroutine, before giving them challenge 7 - the full music player. They were simply expected to create the full music player including the note to frequency subroutine. This turned out to be a daunting task for most students. I have had much greater success having students step through these three challenges. 
One of the most encouraging aspects was some students' response to the final enhanced player. I have received many excellent and creative solutions and the students were justifiably proud of their work. The pseudo-square wave function now used in the second problem was originally part of a student enhancement (see Appendix B). Several students have developed players that included multiple enhancements to the song read in, and that provided the user some nicely laid out choices using MATLAB's menu command as to which enhancements the user would like try. Many students have tackled the random note generation problem. The .wav file distorter also yielded several creative solutions with which students had fun. One solution was a player that played the song backwards and adjusted its tempo.

Less disciplined, or sometimes simply less confident, students tended to skip some of the problems and then end up behind. I let them know in advance the importance of keeping up with each step and provided ways for students to make up lost points toward the end of the term.

A few of the assignments have only a couple of ways to solve them. These less open-ended problems are easily copied, and some care must be taken to avoid plagiarism. The note 2 frequency sub program, the six-note player and the final player all suffer from this issue.

I am currently completing our Institutional Review Board (IRB) approval process to conduct surveys of both the students who are taking the Computer Tools class this term, and students currently enrolled in a $\mathrm{C}$ programming course who took the Computer tools Class in the Fall 2005. Each term I have taught sections of the Computer Tools class using this music/sound theme and other instructors have taught sections using different projects. I will be collecting data on students from both sections for comparison. This surveying is planned for the end of the Spring 2006 semester.

\section{Conclusions}

Using MATLAB's sound capability opens the door for a range of new problems for students to tackle. These problems result in sensory feedback to the students which is enjoyable and something they can relate to even at a beginning level.

Sound and music problems can be arranged in many different ways including: 1 . arranging problems into a series of challenges leading to a final complete program, 2 . using individual problems in the course or 3. providing solutions to these problems as programming examples. The initial music script, the wav file distorter and the graphing problem are particularly well suited to being used independently.

Sound and music problems were always a hit as an example in class where students got to see immediate results. In general the best students in the class have voiced enjoyment of these problems, and students with a background in music often developed extra twists on their programs. They can be a bit intimidating to students without a musical background (even though a music background is not required to complete the problems). It is essential to provide background and support for students lacking musical background. It is also critical to provide clear background on the various mathematical issues relating to sound and waves. 
These challenges teach a range of important issues including: digitization, simple signal processing, practice with using sine and other wave functions, and working with large arrays. However, it is important to take time to teach these issues. The next time I teach this course I will be adding some conceptual homework problems that simply address the concepts of generating digital sine waves and using them to produce sound.

Using a series of challenges allows a way for students to build up their knowledge slowly and avoid being overwhelmed by a complex problem. This constructionist approach does have the limitation that it reduces the open-ended nature of some of the problems. Music and sound is an excellent way to provide a sequential set of challenges.

Appendix A: Example Song Program as given to students

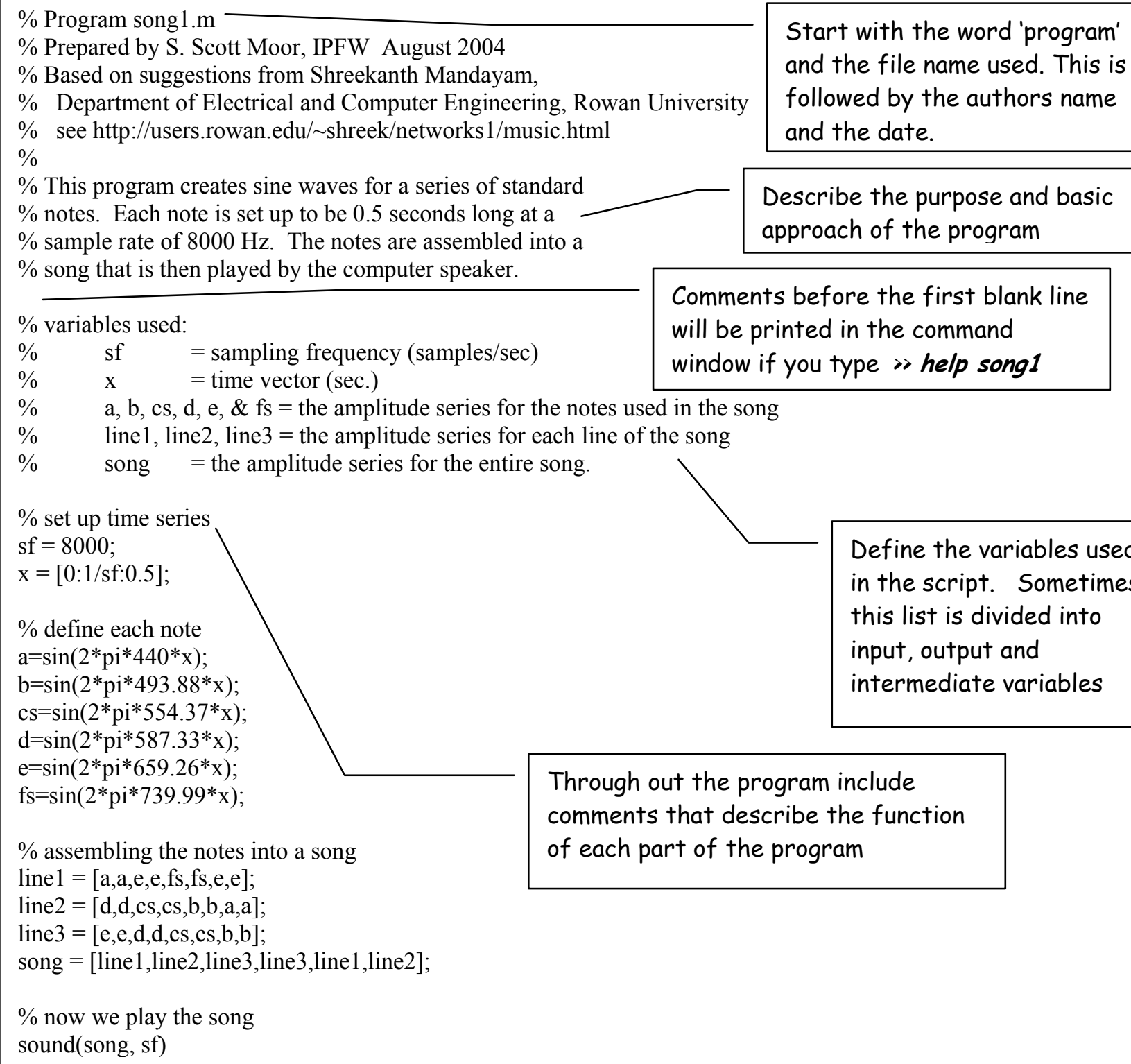

$\% \quad \mathrm{a}, \mathrm{b}, \mathrm{cs}, \mathrm{d}, \mathrm{e}, \& \mathrm{fs}=$ the amplitude series for the notes used in the song
$\% \quad$ line1, line2, line $3=$ the amplitude series for each line of the song

$\begin{array}{ll}\% & \mathrm{a}, \mathrm{b}, \mathrm{cs}, \mathrm{d}, \mathrm{e}, \mathrm{\&} \mathrm{fs}=\text { the amplitude series for the notes used in the } \\ \% & \text { line1, line2, line } 3=\text { the amplitude series for each line of the song }\end{array}$

$\% \quad$ song $\quad=$ the amplitude series for the entire song.

Start with the word 'program' and the file name used. This is followed by the authors name and the date.

Describe the purpose and basic approach of the program

Comments before the first blank line will be printed in the command window if you type $\gg$ help song1 


\section{Appendix B: Pseudo-Square Wave Function}

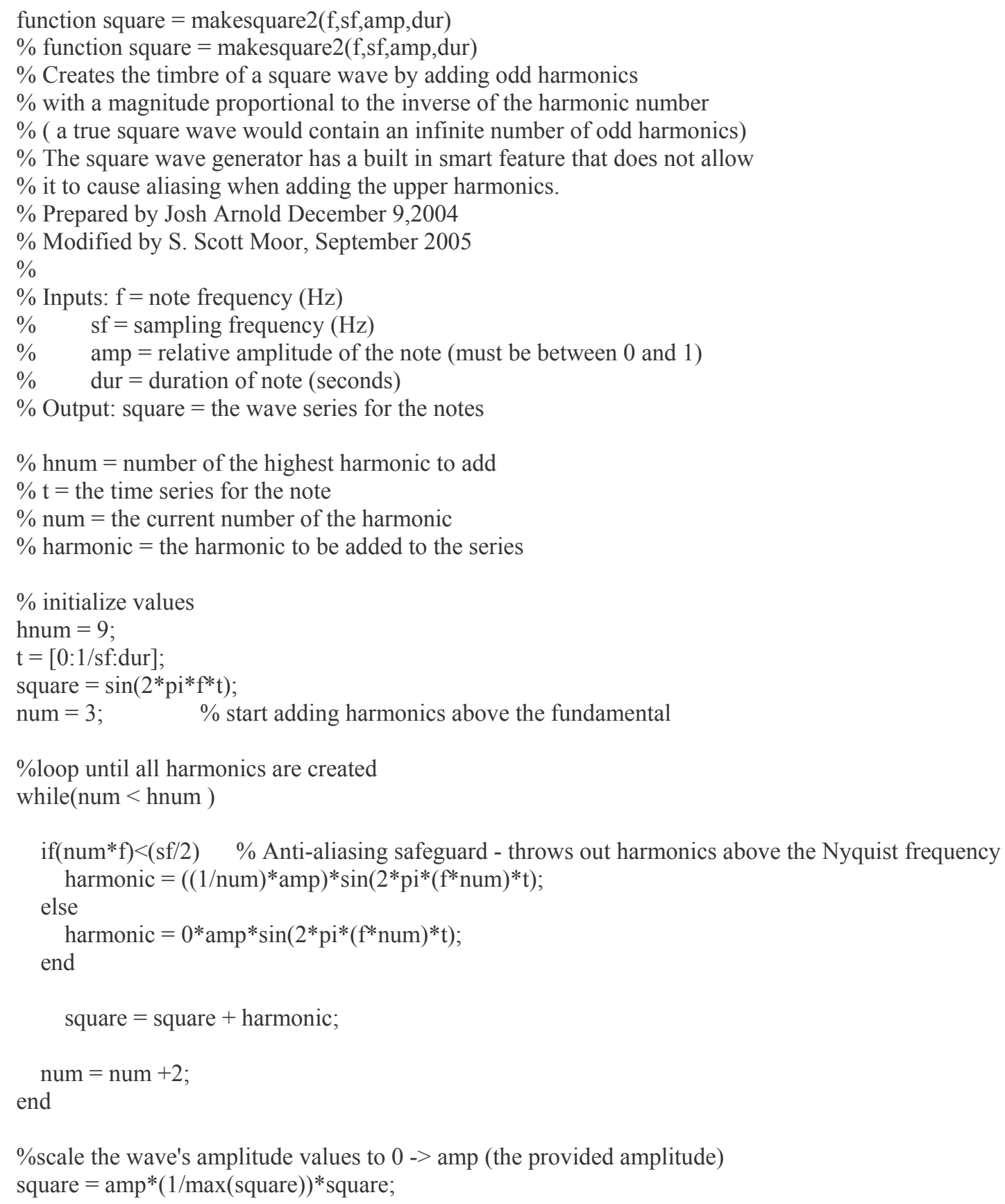

\section{Bibliography}

1. McWilliams, L. H., Silliman, S. E., Pieronek, C., "Modifications to a Freshman Engineering course Based on Student Feedback," Proceedings of the 2004 American Society for Engineering Education Annual Conference \& Exposition, Salt Lake City, UT (June 2004). 
2. Sticklen, J., Amery, M., Exkil, T., Hinds, T. and Urban-Lurain, M. “Application of Object-Centered Scaffolding to Introductory MatLab," Proceedings of the 2004 American Society for Engineering Education Annual Conference \& Exposition, Salt Lake City, UT (June 2004).

3. Baxter, G.W. and Hagenbuch, K.M., "A student project on wind chimes," Phys. Teach. Vol. 36, pp. 204208, (April 1998).

4. Harris, R. W. "Using Wind Chimes to Introduce the Physics Course," Phys. Teach. Vol. 38, pp. 218-219, (April 2000).

5. Peterson, M., "Musical Analysis and Synthesis in MATLAB," MAA's College Mathematics Journal Vol. 35, No. 5, November 2004, p.396-401.

6. Moor, S. "Engineering Design in Five Weeks - Designing a Wind Chime," Proceedings of the 2005 American Society for Engineering Education Annual Conference \& Exposition, Portland, OR (June 2005).

7. Mandayam, S., "Making Music with MATLAB," Networks I, Department of Electrical and Computer Engineering, Rowan University, http://users.rowan.edu/ shreek/networks1/music.html (Fall 1997), accessed January 2006.

8. Thompson, E. "Project for Signal Processing Course," Department of Engineering, Indiana University Purdue University - Fort Wayne, Personal Communication (2005).

9. Moor, S, "Case Study: Renovating a Computer Teaching Laboratory for Active and Cooperative Learning," ASEE 2006 Illinois-Indiana and North Central Joint Section Conference, (Fort Wayne, IN).

10. Moor, S. "Music in MATLAB," http://www.engr.ipfw.edu/ moor/music/.

11. Peterson, M., "Resources to accompany Musical Analysis and Synthesis in MATLAB," http://amath.colorado.edu/pub/matlab/music/, November 2005, accessed January 2006.

12. University of Jyväskylä, "MIDI Toolbox contents," http://www.jyu.fi/musica/miditoolbox/index.html, (C)2004, accessed January 2006. 